\title{
Improvement of Insulin Sensitivity by a Novel Drug Candidate, BGP-15, in Different Animal Studies
}

\author{
Botond Literáti-Nagy, MD, ${ }^{1}$ Kálmán Tory, MD, PhD, ${ }^{2}$ Barna Peitl, MD, PhD, ${ }^{3}$ Ágnes Bajza, MSc, ${ }^{2}$ \\ László Korányi, MD, PhD, DSc, Zsuzsanna Literáti-Nagy, MD, ${ }^{1}$ Philip L. Hooper MD, \\ László Vígh, PhD, DSc, ${ }^{6}$ and Zoltán Szilvássy, MD, PhD, DSc ${ }^{3}$
}

\section{Abstract}

Background: Insulin resistance has been recognized as the most significant predictor of further development of type 2 diabetes mellitus (T2DM). Here we investigated the effect of a heat shock protein (HSP) co-inducer, BGP15 , on insulin sensitivity in different insulin-resistant animal models and compared its effect with insulin secretagogues and insulin sensitizers.

Methods: Insulin sensitivity was assessed by the hyperinsulinemic euglycemic glucose clamp technique in normal and cholesterol-fed rabbits and in healthy Wistar and Goto-Kakizaki (GK) rats in dose-ranging studies. We also examined the effect of BGP-15 on streptozotocin-induced changes in the vasorelaxation of the aorta in Sprague-Dawley rats.

Results: BGP-15 doses of 10 and $30 \mathrm{mg} / \mathrm{kg}$ increased insulin sensitivity by $50 \%$ and $70 \%$, respectively, in cholesterolfed but not in normal rabbits. After 5 days of treatment with BGP-15, the glucose infusion rate was increased in a dose-dependent manner in genetically insulin-resistant GK rats. The most effective dose was $20 \mathrm{mg} / \mathrm{kg}$, which showed a 71\% increase in insulin sensitivity compared to control group. Administration of BGP-15 protected against streptozotocin-induced changes in vasorelaxation, which was similar to the effect of rosiglitazone.

Conclusion: Our results indicate that the insulin-sensitizing effect of BGP-15 is comparable to conventional insulin sensitizers. This might be of clinical utility in the treatment of T2DM.

\section{Introduction}

ThSUlin Resistance plays a major role in the development Lof prediabetes and overt type 2 diabetes (T2DM). ${ }^{1}$ Furthermore, clinical and experimental evidence suggests that both diabetes and insulin resistance cause endothelial dysfunctions, which may diminish the antiatherogenic role of the vascular endothelium..$^{2-4}$ Diabetic endothelial dysfunction is synonymous with decreased endothelium-dependent vasorelaxation to acetylcholine. ${ }^{5}$ A recent large randomized clinical study of patients with stable coronary artery disease and T2DM observed that addition of an insulin-sensitizing drug, a thiazolidinedione or metformin, reduced peripheral artery disease, revascularization surgery, and leg amputations-even when adjusting for improved glycemic control. ${ }^{6}$
The peroxisome proliferator-activated receptor- $\gamma$ (PPAR- $\gamma$ ) agonist the thiazolidinediones (TZDs), so-called insulin sensitizers, enhance insulin action in muscle and fat tissues. The major side effect, seen with troglitazone, the first TZD, is liver damage. Because of this dangerous side effect, the Food and Drug Administration (FDA) removed troglitazone from the market. Two other glitazones, pioglitazone and rosiglitazone, cause weight gain and fluid retention ${ }^{7}$; moreover, rosiglitazone is thought to increase the risk of cardiovascular events. $^{8}$ The side effects and the necessity for a safe and effective insulin sensitizer encourage development of compounds that improve insulin sensitivity through other mechanisms.

BGP-15 [O-(3-piperidino-2-hydroxy-1-propyl)-nicotinic acid], a hydroxylamine derivative, does not belong to the glitazone

\footnotetext{
${ }^{1}$ Drug Research Center Ltd., Balatonfüred, Hungary.

${ }^{2} \mathrm{~N}$-Gene Research and Development Ltd., Budapest, Hungary.

${ }^{3}$ Departments of Pharmacology and Pharmacotherapy, University of Debrecen, Debrecen, Hungary.

${ }^{4}$ Department of Medical Chemistry, Molecular Biology and Pathobiochemistry, Semmelweis University Budapest, Budapest, Hungary.

${ }^{5}$ Division of Endocrinology, Metabolism, and Diabetes, School of Medicine, University of Colorado, Anschutz Medical Campus, Aurora, Colorado.

${ }^{6}$ Biological Research Center, Hungarian Academy of Sciences, Institute of Biochemistry, Szeged, Hungary.
} 
family. Receptor binding experiments with BGP-15 do not interfere with ligand-inducible PPAR $-\alpha,-\gamma$, or $-\delta$ signaling. ${ }^{9,10}$ The insulin-sensitizing effect of BGP-15 in $o b / o b$ mice activates HSP72 in skeletal muscles and prevents c-jun aminoterminal kinase (JNK) phosphorylation and subsequent insulin resistance. ${ }^{11}$ Furthermore, our previous results indicate that BGP-15 may have additional cardiovascular protective activity, i.e., it prevented ischemia/reperfusioninduced heart injury and restored vascular responsiveness in insulin resistance. ${ }^{12-14}$ Recent studies demonstrate that BGP-15 confers protection against rapid pacing-induced atrial fibrillation in a Drosophila melanogaster model of cardiac arrhythmias. $^{12,15}$

The aim of this series of experiments was to assess the insulin-sensitizing effect of BGP-15 alone, and in combination as well, in comparison with oral antidiabetics such as metformin, rosiglitazone, and glibenclamide. Furthermore, we studied the therapeutic effect of BGP15 and rosiglitazone on vasorelaxation induced by acetylcholine in aortic preparations isolated from streptozotocin (STZ)-induced diabetic rats.

\section{Materials and Methods}

\section{Experimental animals}

Adult, male, white New Zealand rabbits, weighing 3$3.5 \mathrm{~kg}$, adult male Wistar and Goto-Kakizaki (GK) rats weighing 220-320 grams and male Sprague-Dawley rats weighing 270-290 grams (aged 9-14 weeks), housed in an animal room (12-hr light/dark periods a day, temperature of $22-25^{\circ} \mathrm{C}$, humidity of $50-70 \%$ ) and fed commercial laboratory chow and tap water ad libitum were used after a 2-week adaptation period.

Food was withdrawn at least $12 \mathrm{hr}$ prior to commencement of experiments to determine insulin sensitivity. A bolus injection of STZ $50 \mathrm{mg} / \mathrm{kg}$ intravenously (i.v.) was administered via tail vein 12 weeks before use.

\section{Preparation of isolated thoracic aorta}

Male Sprague-Dawley rats were anesthetized with sodium pentobarbital (Nembutal ${ }^{\circledR}$, Sigma, $60 \mathrm{mg} / \mathrm{kg}$ ). After thoracotomy, the thoracic aorta was removed and placed in ice-cold Krebs solution and continuously aerated with 95\% $\mathrm{O}_{2}, 5 \% \mathrm{CO}_{2}$. The descending thoracic aorta was cut into rings approximately $5 \mathrm{~mm}$ in length. Ring preparations $(n=4)$ were set up in parallel for isometric tension measurement by maintaining the tissues under a resting preload tension of 2 grams, in 10-mL organ baths (thermostatically controlled for $37 \pm 0.2^{\circ} \mathrm{C}$ ) containing Krebs-Henseleit solution ( $\mathrm{pH} 7.4$ ) and maintained under oxygenation at $37^{\circ} \mathrm{C}$. Precontraction of the aorta was induced by phenylephrine. This maximum constriction was previously determined by increasing dose of the $\alpha$-adrenergic agonist. Maximum vasorelaxation was obtained by increasing the dose of acetylcholine to the precontracted vascular preparation. Tension measurement was carried out with Isosys System (EXP-D isolated organ amplifier, AIF-01 computer interface and IBM-compatible personal computer Experimetria Ltd., Budapest).

\section{Hyperinsulinemic euglycemic glucose clamp}

Whole-body insulin sensitivity was determined by hyperinsulinemic euglycemic glucose clamp (HEGC) method as de- scribed. ${ }^{16}$ Human regular insulin was infused at a constant rate (13-15 mU/kg per min, Actrapid; Novo Nordisk, Copenhagen, Denmark) via one of the venous catheters over $120 \mathrm{~min}$. This insulin infusion rate yielded plasma insulin immunoreactivity of $100 \pm 5 \mu \mathrm{U} / \mathrm{mL}$ in the steady state. Blood samples $(0.2 \mathrm{~mL})$ were taken from the arterial cannula for blood glucose concentration measurement at 10-min intervals. Blood glucose concentration was maintained constant $(5.5 \pm 0.5 \mathrm{mmol} / \mathrm{L})$ by a variable rate of glucose infusion via the second venous cannula. When blood glucose had stabilized for at least 20-30 min, this condition was defined as the steady state. In this state, additional blood samples $(0.3 \mathrm{~mL})$ were taken for plasma insulin determination three times at 10-min intervals. The glucose infusion rate ( $\mathrm{mg} / \mathrm{kg}$ per $\mathrm{min}$ ) during the steady state was the measure of glucose disposal characterizing insulin sensitivity.

\section{Effect of BGP-15 on insulin sensitivity in normal and cholesterol-fed rabbits}

The rabbits were randomized into two groups. One group of the animals was continued to be fed normal rabbit chow, whereas the other group was fed chow enriched with 1.5\% cholesterol over a period of 8 weeks. Each group was divided into six treatment groups $(n=6)$; one of them was untreated (without treatment) and the others were treated with BGP-15 at 5, 10, 20, 30, or $50 \mathrm{mg} / \mathrm{kg}$ per os, once a day for 5 days. BGP-15 was provided by N-Gene Research Laboratories Ltd. (Budapest, Hungary).

\section{Effect of BGP-15, rosiglitazone and metformin on insulin sensitivity in healthy Wistar and in GK rats}

The experiments were carried out with male Wistar and GK rats. Oral daily doses of BGP-15 $(5-30 \mathrm{mg} / \mathrm{kg})$, rosiglitazone $\left(2 \mathrm{mg} / \mathrm{kg}\right.$ Avandia ${ }^{\circledR}$, SmithKline Beecham plc, Brentford Middlesex, UK), metformin $\left(100 \mathrm{mg} / \mathrm{kg}\right.$, Adimet $^{\circledR}$, Ratiopharm, Hungary), and distilled water (control group) were applied for 5 days. Insulin sensitivity was assessed by HEGC prior to and at the end of the treatment period 4-6 hr after the last BGP-15 dose. Four groups were used to test the effect of BGP-15 $(5,10$, 20 , and $30 \mathrm{mg} / \mathrm{kg}$ ) by the HEGC procedure, whereas two separate groups were used to test the effect of rosiglitazone $(2 \mathrm{mg} / \mathrm{kg})$ and metformin $(100 \mathrm{mg} / \mathrm{kg})$ by this method. The doses of these latter drugs were selected as described. ${ }^{17}$

\section{Effect of BGP-15 on insulin sensitivity in combination with a sulfonylurea antidiabetic drug in GK rats}

The animals were divided into six treatment groups of seven animals each. Animals were treated once a day orally with distilled water (control group), BGP-15 (3, 10, and $30 \mathrm{mg} / \mathrm{kg})$ alone, glibenclamide $\left(1 \mathrm{mg} / \mathrm{kg}\right.$ Gilemal $^{\circledR}$, PannonPharma, Hungary) alone, and BGP-15 (10 mg/ $\mathrm{kg})$ in combination with glibenclamide $(1 \mathrm{mg} / \mathrm{kg})$ for 5 days. Control rats received $1.0 \mathrm{~mL}$ of distilled water. Insulin sensitivity was assessed by HEGC prior to and at the end of treatment period 4-6 hr after the last BGP-15/glibenclamide dose.

\section{The effects of BGP-15 on ex vivo relaxation of aorta obtained from normal and STZ-diabetic rats}

STZ-treated Sprague-Dawley rats were considered diabetic and retained for experiments if their blood glucose 

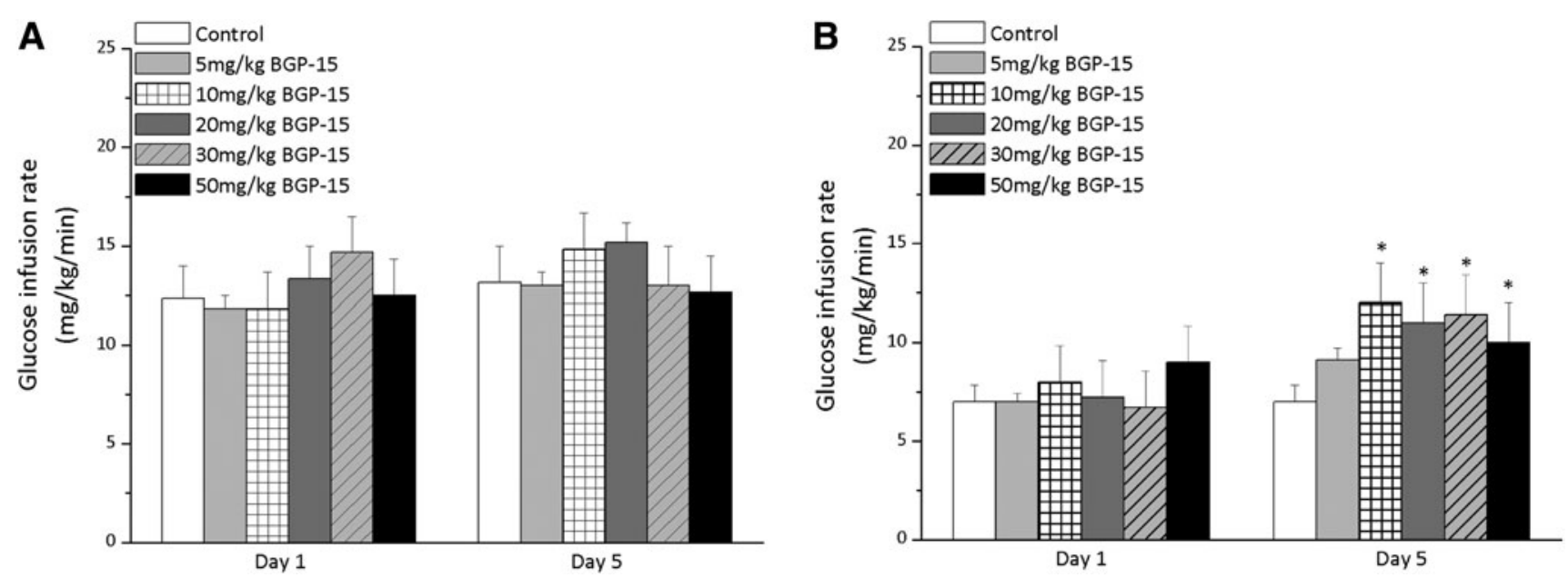

FIG. 1. Effect of BGP-15 on insulin sensitivity in normal (A) and cholesterol-fed rabbits (B). The results are expressed as means \pm standard deviation (SD) $\left(n=6\right.$ animals per group). $\left.{ }^{*}\right)$ Significantly different from the control group, $P<0.05$.

concentration was higher than $20 \mathrm{mmol} / \mathrm{L}$. BGP-15 (in doses of 20 and $50 \mathrm{mg} / \mathrm{kg})$, and rosiglitazone $(4 \mathrm{mg} / \mathrm{kg})$ were given to STZ diabetic rats orally over 5 days. Agematched, saline-treated, male Sprague-Dawley rats served as controls.

\section{Statistical analysis}

The data were analyzed with one-way analysis of variance (one-way ANOVA) followed by the Student $t$-test modified according to the Bonferroni method for repeated measures. ${ }^{18}$ The comparisons between treatment groups were calculated with one-way ANOVA pairwise analysis. Differences were considered statistically significant at $P<0.05$.

\section{Results}

\section{Insulin-sensitizing effects of BGP-15 in normal and cholesterol-fed rabbits}

Repetitive oral doses of BGP-15 (once a day) induced a significant increase in insulin sensitivity during 5-day treatments with $10,20,30$, and $50 \mathrm{mg} / \mathrm{kg}$ of BGP-15, respectively, in cholesterol-fed but not in normal rabbits. BGP-15 doses of 10 and $30 \mathrm{mg} / \mathrm{kg}$ were the most effective doses because these showed a $50 \%$ and a $70 \%$ increase in insulin sensitivity, respectively. The lowest dose studied, $5 \mathrm{mg} / \mathrm{kg}$ per day, had a moderate effect, but it did not reach the level of statistical significance (Fig. 1).

\section{Effect of BGP-15, rosiglitazone, and metformin on insulin sensitivity in GK rats}

All of the applied doses of BGP-15 showed a significant improvement of insulin sensitivity, which was dose-dependent up to the level of $20 \mathrm{mg} / \mathrm{kg}$ in genetically insulin-resistant GK rats. The most effective dose observed at $20 \mathrm{mg} / \mathrm{kg}$ of BGP-15 showed a 71\% increase in glucose infusion rate after 5 days of treatment. While BGP-15 improved insulin sensitivity more than each of the other drugs on the market (rosiglitazone and metformin), BGP-15 proved statically superior to metformin and trended better than rosiglitazone (Fig. 2).

\section{Effect of BGP-15 on insulin sensitivity in combination with glibenclamide in GK rats}

The doses of 10 and $30 \mathrm{mg} / \mathrm{kg}$ BGP-15 caused a significant increase in peripheral glucose uptake after 5 days of treatment. BGP-15 $(10 \mathrm{mg} / \mathrm{kg})$ in combination with glibenclamide $(1.0 \mathrm{mg} / \mathrm{kg})$ also increased insulin sensitivity. This combined effect of BGP-15 and glibenclamide yielded a 97\% increase in glucose infusion rate compared to the control group (Fig. 3).

\section{The effects of BGP-15 on ex vivo relaxation of aortae obtained from normal and STZ diabetic rats}

The decreased maximum vasorelaxation effect of acetylcholine in the 9- to 14-week-old STZ diabetic rats was normalized by 5 days of BGP-15 (20 and $50 \mathrm{mg} / \mathrm{kg}$ ) and rosiglitazone $(4 \mathrm{mg} / \mathrm{kg})$ treatment. BGP-15 $(20 \mathrm{mg} / \mathrm{kg})$ produced a rosiglitazone-like effect both in shape and strength. Oral administration of BGP-15 in $20-$ or $50-\mathrm{mg} / \mathrm{kg}$ doses given for 5 days protected against STZ-induced diabetic changes in the vasorelaxation of the aorta. The effect of BGP15 is comparable to that of rosiglitazone (Fig. 4).

\section{Discussion}

We evaluated the effect of BGP-15 on insulin sensitivity in New Zealand white rabbits, Wistar, and GK rats, and Sprague-Dawley rats in comparison with metformin, rosiglitazone, and glibenclamide. As an insulin sensitizer, BGP-15 outperformed metformin and equaled or superseded the rosiglitazone drug effect. Additionally, our compound proved to be effective in increasing insulin sensitivity when combined with a sulfonylurea agent. Five days of treatment with multiple different doses clearly showed the insulinsensitizing effect of BGP-15 in cholesterol-fed rabbits but not in normal rabbits, which served as controls. This series of experiments confirmed that BGP-15 had a beneficial effect only in the insulin-resistant state.

BGP-15 treatment restored cholinergic vasorelaxation in aorta obtained from STZ diabetic rats. Vascular smooth muscle has been recently regarded as a nonclassical insulinsensitive tissue. Diabetes impairs endothelium-dependent 


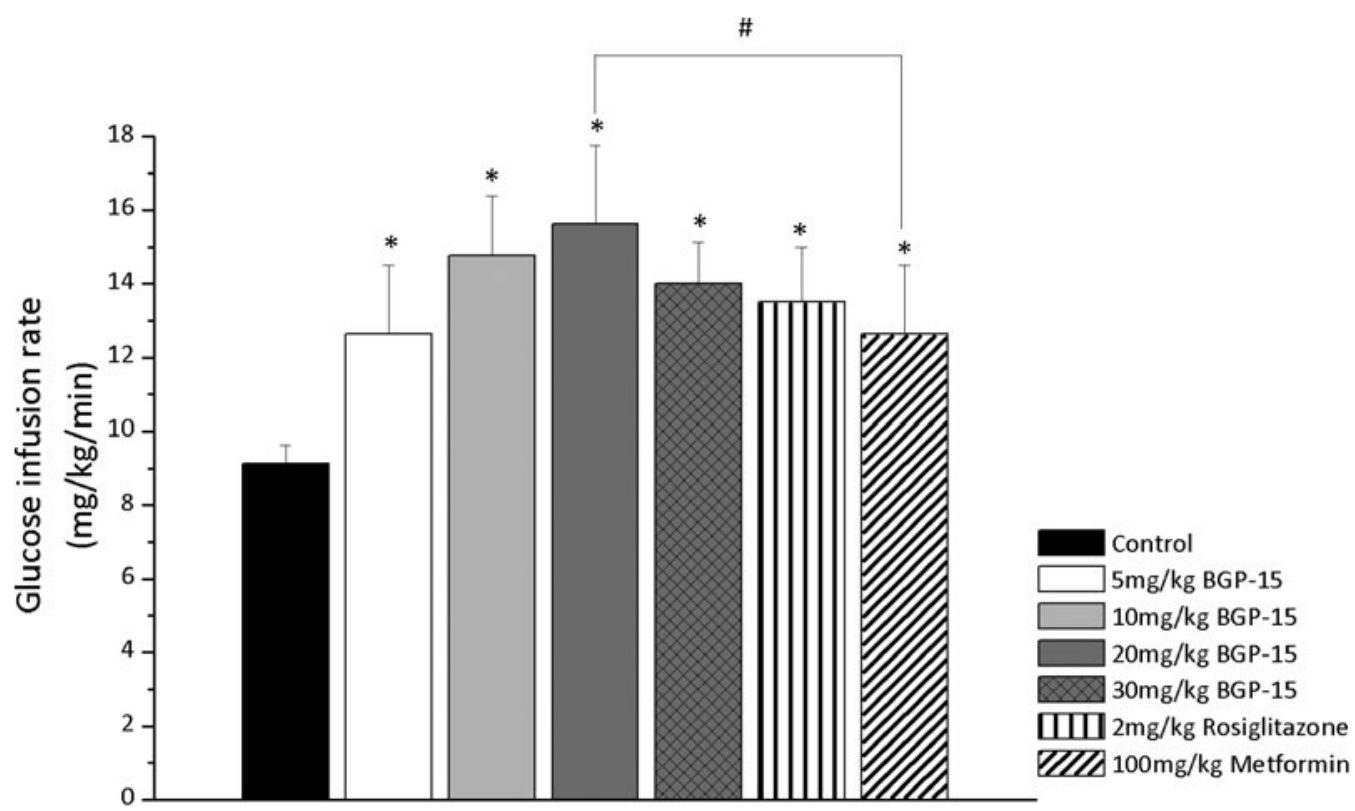

FIG. 2. Effect of BGP-15 on insulin sensitivity in Goto-Kakizaki (GK) rats with the hyperinsulinemic euglycemic glucose clamp (HEGC) method. Data are shown as means \pm standard deviation obtained with six animals per group. (*) Significantly different from the control group, $P<0.05$. (\#) Significantly different from the metformin group, $P=0.025$. Insulin sensitivity improvement with BGP-15 $(20 \mathrm{mg} / \mathrm{kg})$ compared to rosiglitazone showed a trend to a greater effect with BGP-15 ( $p=0.07)$, but the improvement was not statistically significant. Data were analyzed with one-way analysis of variance (ANOVA) followed by the Student $t$-test modified according to the Bonferroni method for repeated measures. The comparisons between treatment groups were calculated with one-way ANOVA pairwise analysis.

vasorelaxation, ${ }^{5}$ which can be prevented by rosiglitazone administration. ${ }^{19}$ Rosiglitazone may act through increased nitric oxide (NO) bioavailability. ${ }^{19}$ It has been demonstrated that insulin may restore neuronal nitric oxide synthase (NOS) expression in STZ-induced diabetic rats. ${ }^{20}$ Moreover, restoration of acetylcholine vasorelaxation by BGP-15 could be extinguished by 7-nitro-indazole, an inhibitor of neuronal
NOS. ${ }^{21}$ These data are in line with our observation that BGP15 can induce the expression of neuronal NOS in endothelial cells and that the BGP-15-induced increase in insulin sensitivity can be abolished by 7-nitro-indazole (unpublished). It is suggested that BGP-15 may ameliorate diabetes-induced impairment in vasorelaxation through a neuronal NOSdependent mechanism.

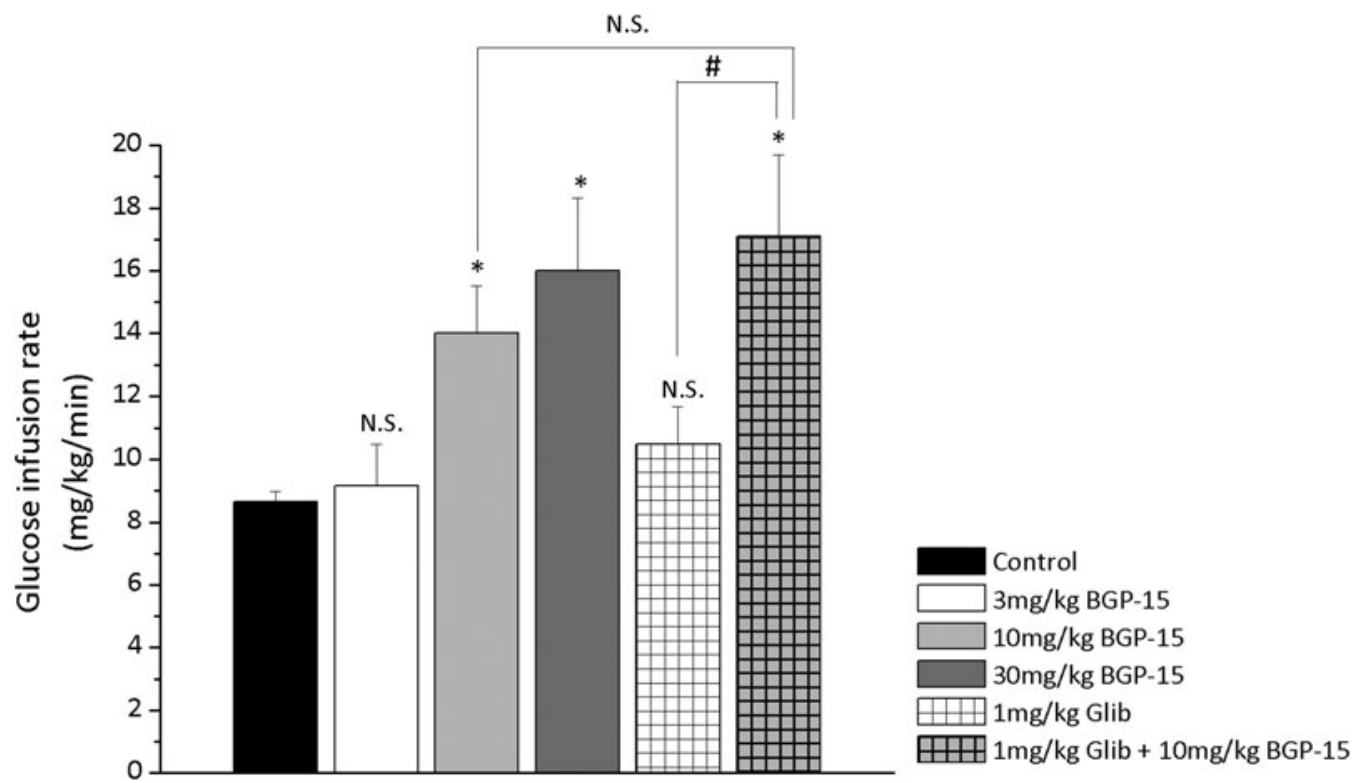

FIG. 3. The combined effect of BGP-15 and glibenclamide (Glib) on insulin sensitivity was measured by hyperinsulinemic euglycemic glucose clamp in Goto-Kakizaki insulin-resistant rats. Data are mean \pm standard deviation (SD) $(n=7$ animals per group). $\left(^{*}\right)$ Significantly different from the control group. $\left({ }^{*}\right)$ Shows a significant difference BGP + glibenclamide versus glibenclamide alone, $P<0.05$. N.S., not significant. 


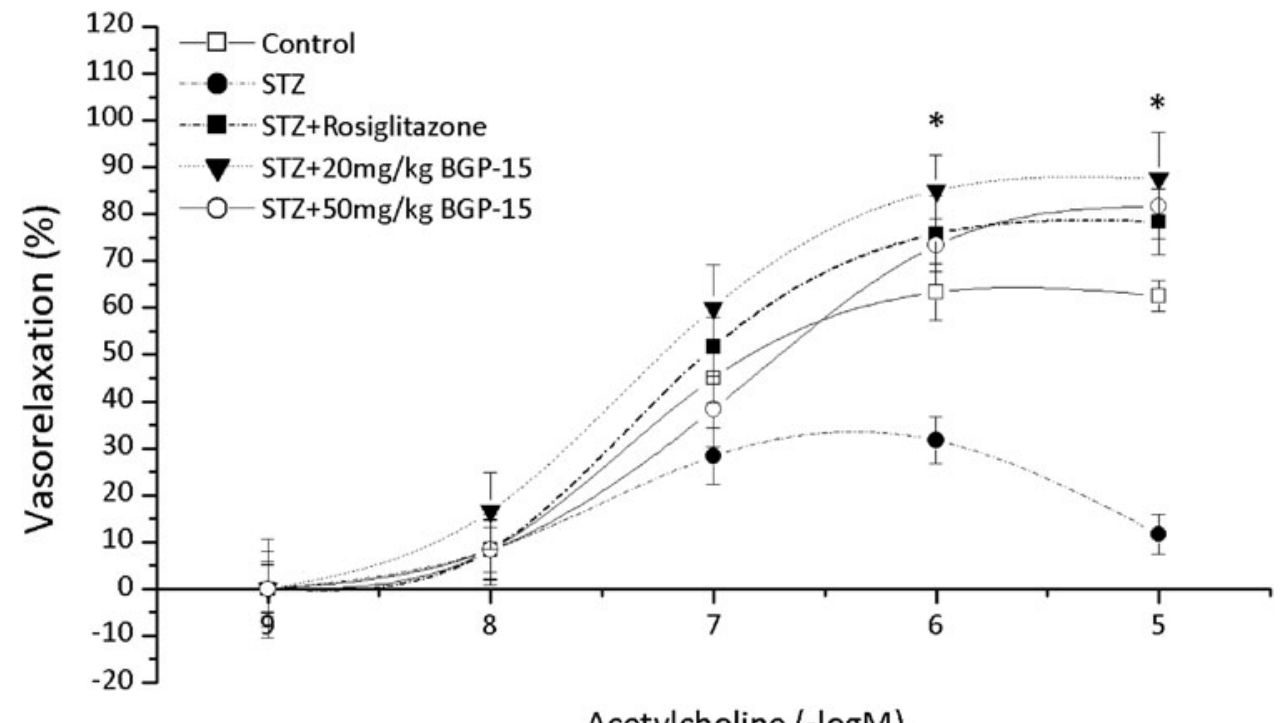

Acetylcholine $(-\log M)$

FIG. 4. The percentage of vasorelaxation by acetylcholine was calculated as $100 \%$ of the maximal contraction at steady state induced by phenylephrine $\mathrm{EC}_{50}$ (phenylephrine concentration producing $50 \%$ of maximal tension). Data were expressed as means \pm standard error of the mean (SEM), and analyzed with one-way analysis of variance (ANOVA) followed by multiple comparison post hoc tests. $\left(^{*}\right)$ Significantly different from the streptozotocin (STZ) group, $P<0.05$.

Hydroximic acid derivatives represent a new class of insulin sensitizers and have entered phase II clinical studies. ${ }^{22}$ BGP-15 is the first of a new class of insulin sensitizers of the hydroximic acid derivative family, also known as "chaperone inducers" or "coinducers." ${ }^{23-25}$ Mode of action studies showed that BGP-15 increases the expression of heat shock proteins (HSP-90 $\alpha$, HSP-72) and constitutive (c) NOSs (endothelial NOS, neuronal NOS) in cell cultures. ${ }^{26}$ BGP-15 inhibited JNK and increased the level of HSP activity of cNOS in vitro and in vivo. ${ }^{26,27}$ Decreased HSP expression is one of the cellular changes characteristic of diabetes. ${ }^{28-30}$ Not only are the levels of HSP72 decreased in T2DM, ${ }^{29-31}$ but wholebody glucose utilization is significantly correlated with HSP72 levels. ${ }^{29}$ HSP72 acts on insulin sensitivity by inhibiting the inflammatory cascades, which activate the IкB kinase $\beta$ (IKK- $\beta$ ) and the inflammatory signaling protein JNK, which can phosphorylate on tyrosine residues of insulin receptor substrates and thus inhibit insulin signaling. ${ }^{25,32}$ Inflammation via the JNK pathway plays a pivotal role in the development of insulin resistance. ${ }^{33}$ Furthermore, BGP-15 enhances mitochondrial biogenesis and improves mitochondrial dysfunction in pathological metabolic states. ${ }^{34}$

The HSP chaperone induction effect of hydroximic acid derivatives is based upon a direct interaction with heat shock factor-1 (HSF-1). ${ }^{35}$ This key transcription factor induces expression of heat shock proteins; they bind to HSF-1 and stabilize the binding of HSF-1 to its DNA response element. ${ }^{35}$ The importance of HSF-1, HSPs, and inflammation as they relate to insulin signaling and T2DM has been recognized recently. ${ }^{36}$ The role of HSP-72 in the development of insulin resistance was demonstrated by Chung et al. in knockout $o b /$ $o b$ mice. A 15-day-long BGP-15 treatment significantly reduced fasting blood glucose and insulin levels and increased insulin sensitivity as assessed by glucose clamps. ${ }^{11}$

Where does BGP-15 fit into diabetic therapeutic armamentarium? Insulin resistance appears before the development of T2DM, a disease that often is accompanied by serious long- term complications and eventually heavy health economic consequences due to the tremendous cost of treatment. Numerous large studies have shown that the best way to reduce the expenditure is through prevention during the "prediabetic" stage or in the early stage of diabetes through change in lifestyle or pharmaceutical intervention. ${ }^{37}$ Although changes in lifestyle have a greater positive effect on the restoration of insulin sensitivity, the more readily accepted insulin sensitizer drugs have had a big impact not only on the treatment but on disease prevention as well. Among insulin sensitizers, metformin ${ }^{38}$ and the TZDs have been tested in these fields. The adverse effects of PPAR agonists such as TZDs have become an increasing problem in diabetes patients with cardiovascular disease (CVD). Rosiglitazone therapy was associated with a significantly increased risk of heart attack [odds ratio $(\mathrm{OR})=1.43,95 \%$ confidence interval $(\mathrm{CI}), 1.03-1.98 ; P=0.03)$, and an even higher risk of death from all cardiovascular diseases $(\mathrm{OR}=1.64)^{8}$.

Pioglitazone treatment, in contrast, showed significant protection from all-cause mortality. ${ }^{39}$ However data regarding the increased risk in cardiovascular events with TZDs are still inconsistent. Recently pioglitazone was significantly associated with an increased risk of bladder cancer. ${ }^{40}$

Glucagon-like peptide-1-based therapy is gaining widespread use for T2DM, although there are concerns about risks for pancreatitis and pancreatic and thyroid cancers. There are also concerns that dipeptidyl peptidase- 4 inhibitors might be oncogenic, given their effects on immune function, ${ }^{41}$ but they need further elucidation.

Our results suggest that BGP-15 could be a promising drug candidate for improving insulin resistance and thus T2DM. Moreover it could be therapeutic in the prevention of T2DM and in the treatment of diabetic vascular complications. Our findings support the need for future investigations of BGP-15 therapy of T2DM patients in phase II-III studies, administered alone or combined with other agents. 


\section{Author Disclosure Statement}

No competing financial interests exist.

\section{References}

1. DeFronzo RA. The triumvirate: $\beta$-cell, muscle, liver. A collusion responsible for NIDDM. Diabetes 1988;37:667-687.

2. Calles-Escandon J, Cipolla M. Diabetes and endothelial dysfunction: A clinical perspective. Endocr Rev 2001;22: 36-52.

3. Baron AD. Insulin resistance and vascular function. J Diabetes Complications 2002;16:92-102.

4. Vincent MA, Montagnani M, Quon MJ. Molecular and physiologic actions of insulin related to production of nitric oxide in vascular endothelium. Curr Diab Rep 2003;3:279_ 288.

5. Feener EP, King GL. Endothelial dysfunction in diabetes mellitus: Role in cardiovascular disease. Heart Fail Monit 2001;1:74-82.

6. Althouse AD, Abbott JD, Sutton-Tyrrell K, et al. Favorable effects of insulin sensitizers pertinent to peripheral arterial disease in type 2 diabetes: Results from the bypass angioplasty revascularization investigation 2 diabetes (BARI 2D) trial. Diabetes Care 2013;36:3269-3275.

7. Hollenberg NK. Considerations for management of fluid dynamic issues associated with thiazolidinediones. Am J Med 2003;8(Suppl 8A):111S-115S.

8. Nissen SE, Wolski K. Effect of rosiglitazone on the risk of myocardial infarction and death from cardiovascular causes. N Engl J Med 2007;356:2457-2471.

9. Chen JD, Evans RM. A transcriptional co-repressor that interacts with nuclear hormone receptors. Nature 1995;377: 454-457.

10. Nagy L, Kao HY, Love JD, et al. Mechanism of corepressor binding and release from nuclear hormone receptors. Genes Dev 1999;13:3209-3216.

11. Chung J, Nguyen AK, Henstridge DC, et al. HSP72 protects against obesity-induced insulin resistance. Proc Natl Acad Sci USA 2008;105:1739-1744.

12. Crul T, Toth N, Piotto $\mathrm{S}$, et al. Hydroximic acid derivatives: Pleiotrophic HSP co-inducers restoring homeostasis and robustness. Curr Pharm Des 2013;19:309-346.

13. Halmosi R, Berente Z, Osz E, et al. Effect of poly(ADPribose) polymerase inhibitors on the ischemia-reperfusioninduced oxidative cell damage and mitochondrial metabolism in Langendorff heart perfusion system. Mol Pharmacol 2001;59:1497-1505.

14. Szabados E, Literati-Nagy P, Farkas B, et al. BGP-15, a nicotinic amidoxime derivate protecting heart from ischemia reperfusion injury through modulation of poly(ADP-ribose) polymerase. Biochem Pharmacol 2000;59:937-945.

15. Zhang D, Ke L, Mackovicova K, et al. Effects of different small HSPB members on contractile dysfunction and structural changes in a Drosophila melanogaster model for atrial fibrillation. J Mol Cell Cardiol 2011;51:381-389.

16. Porszasz R, Legvari G, Pataki T, et al. Hepatic insulin sensitizing substance: A novel sensocrine mechanism to increase insulin sensitivity in anaesthetized rats. $\mathrm{Br} J$ Pharmacol 2003;139:1171-1179.

17. Cittadini A, Napoli R, Monti MG, et al. Metformin prevents the development of chronic heart failure in the SHHF rat model. Diabetes 2012;61:944-953.

18. S Wallenstein, CL Zucker, JL Fleiss. Some statistical methods useful in circulation research. Circ Res 1980;47:1-9.
19. Bagi Z, Koller A, Kaley G. PPARgamma activation, by reducing oxidative stress, increases $\mathrm{NO}$ bioavailability in coronary arterioles of mice with type 2 diabetes. Am J Physiol Heart Circ Physiol 2004;286:H742-H748

20. Yu WJ, Juang SW, Chin WT, et al. Insulin restores neuronal nitric oxide synthase expression in streptozotocin-induced diabetic rats. Life Sci 2000;68:625-634.

21. Chinellato A, Froldi G, Caparrotta L, et al. Pharmacological characterization of endothelial cell nitric oxide synthase inhibitors in isolated rabbit aorta. Life Sci 1998;62:479-490.

22. Literáti-Nagy B, Kulcsár E, Literáti-Nagy Z, et al. Improvement of insulin sensitivity by a novel drug, BGP-15, in insulin-resistant patients: A proof of concept randomized double-blind clinical trial. Horm Metab Res 2009;41:374-380.

23. Vígh L, Literáti PN, Horváth I, et al. Bimoclomol: A nontoxic, hydroxylamine derivative with stress proteininducing activity and cytoprotective effects. Nat Med 1997;3:1150-1154.

24. Kieran D, Kalmar B, Dick JR, et al. Treatment with arimoclomol, a coinducer of heat shock proteins, delays disease progression in ALS mice. Nat Med 2004;10:402-405.

25. MacCarty MF. Induction of heat shock proteins may combat insulin resistance. Med Hypotheses 2006;66:527-534.

26. Kolonics A, László L, Ábrahám Cs S, et al. BGP-15, a hydroximic acid derivative induces HSP72, activates neuronal NOS and preserves mitochondria number in hyperglycemic rat brain endothelial cell models. Fundam Clin Pharmacol 2004;18(Suppl 1):p. 67.

27. Kolonics A, Literati-Nagy P, Peitl B, et al. BGP-15, a new type of insulin sensitizer. Diabetes 2006;55(Suppl 1):2091.

28. Patti ME, Butte A, Cusi K, et al. Analysis of differential gene expression in skeletal muscle from subjects with insulin resistance and type 2 diabetes. Diabetes 2001;50(Suppl 2): A247.

29. Kurucz I, Morva A, Vaag A, et al. Decreased expression of heat shock protein 72 in skeletal muscle of patients with type 2 diabetes correlates with insulin resistance. Diabetes 2002;51:1102-1109.

20. Soti C, Nagy E, Giricz Z, et al. Heat shock proteins as emerging therapeutic targets. Br J Pharmacol 2005;146:769.

31. Bruce CR, Carey AL, Hawley JA, et al. Intramuscular heat shock protein 72 and heme oxygenase- 1 mRNA are reduced in patients with type 2 diabetes. Diabetes 2003;52: 2338-2345.

32. Park HS, Lee JS, Huh SH, et al. Hsp72 functions as a natural inhibitory protein of c-Jun N-terminal kinase. EMBO J 2001;20:446-456.

33. Hirosumi J, Tuncman G, Chang L, et al. A central role for JNK in obesity and insulin resistance. Nature 2002;420: 333-336.

34. Kolonics A, Horváth T, Kiss E, et al. Mitochondrial status of lymphocytes shows correlation with metabolic state. Diabetes 2006;55(Suppl 1):A143-A144.

35. Hargitai J, Lewis H, Boros I, et al. Bimoclomol, a heat shock protein co-inducer, acts by the prolonged activation of heat shock factor-1. Biochem Biophys Res Commun 2003;307: 689-695.

36. Hooper PL, Hooper PL. Inflammation, heat shock proteins, and type 2 diabetes. Cell Stress Chaperones 2009;14:113-115.

37. Gillies CL, Abrams KR, Lambert PC, et al. Pharmacological and lifestyle interventions to prevent or delay type 2 diabetes in people with impaired glucose tolerance: systematic review and meta-analysis. Br Med J 2007;10:299.

38. Ou H-Y, Cheng J-T, Yu E-H, et al. Metformin on insulin sensitivity and plasma $\beta$-endorphin in human subjects. Horm Metab Res 2006;38:106-111. 
39. Mannucci E, Monami M, Lamanna C, et al. Pioglitazone and cardiovascular risk. A comprehensive meta-analysis of randomized clinical trials. Diabetes Obes Metab 2008;10:1221-1238.

40. Neumann A, Weill A, Ricordeau P, et al. Pioglitazone and risk of bladder cancer among diabetic patients in France: A population-based cohort study. Diabetologia 2012;55:1953-1962.

41. Elashoff M, Matveyenko AV, Gier B, et al. Pancreatitis, pancreatic, and thyroid cancer with glucagon-like peptide1-based therapies. Gastroenterology 2011;141:150-156.
Address correspondence to: Philip L. Hooper MD

Department of Endocrinology University of Colorado Health Sciences Center PO Box 245

Glen Haven, CO 80532

E-mail: phoopermd@gmail.com 